\title{
An Analysis on the Impact of Chinese Folk Arts on Modern Art Design
}

\author{
Yongqiang Wang \\ School of Art and Design \\ Huanghe Science and Technology College \\ Zhengzhou, Henan, China
}

\begin{abstract}
Chinese folk arts, also known as Group of the Chinese nation culture and art, include kinds of arts, contain a lot of contents. With rich connotation and a long history, they mainly reflect people's basic necessities of life, local customs and Social etiquette. Currently, modern art design has been developing flourishingly, while Chinese folk arts play significant roles in it. In this paper, the author discusses the relationship between Chinese folk arts and modern art design, aims at pointing out that inheriting the essence of Chinese folk arts can improve modern art design better, and make it more nationally distinctive among world art community.
\end{abstract}

Keywords-group culture; Chinese folk arts; world art; modern art design

\section{INTRODUCTION}

Chinese folk arts are key parts of Chinese traditional culture and cultural symbol. They show vulgar art thoughts and language of laboring people. With the change of folk art social basis, modern art products becoming mainstream of public and cultural life. Taking full use of the essence of Chinese folk arts makes modern art design more colorful, and greatly promotes their development.

\section{CONCERNING DEVELOPMENT OF CHINESE FolK ARTS AND MODERN ART DESIGN}

Nowadays the multi-culture developing rapidly, science and technology promotes the generation of new technology. Chinese folk arts, the traditional culture form, are fused with modern art design inevitably, which brings great changes to people of the age. New technology accelerates modern art design's development, strikes Chinese folk arts to some extent as well, just as revolutionary advances of printing technology allow manual printing to gradually withdrew from the stage of history, making print really start to serve the people and widely use in social life. It is exactly the development of print that makes kinds of graphic design develop greatly. After that, the emergence of photography makes modern art design more and more excellent. Till now, the electronic media comes into being, adding brilliance to modern art design's present splendor. Its colorful scene visual art forms enrich the audience's audio-visual language greatly and become an important part of the modern art design. As is known to all, we enter network age now, the emergence and development of the Internet makes new form of art design arise at the moment and infinitely expands the scope of modern art design, making it develop in the field of world, like we get to web design and multimedia art every day.

Modern art design develops under the influence of western modern art design thought in twentieth century. It breaks traditional aesthetic conception substantially because big industrial production and development of modern civilization and closely relates to modern social life. Generally speaking, western modern art design pays much attention to new forms of visual language, it innovates in forms of thinking, techniques of expression, creative ideas and relevant media, differs from traditional art greatly. In other words, western modern art design has a deep impact on modern art design.

Along with the advance of modern industrial civilization, the Chinese folk arts based on folk culture lose their dependence in ecological environment, gradually withdraw from historical stage. Take traditional Chinese New-year wood engravings for example, once was used to decorate houses to celebrate the festival and was used as the media of public communication, because of its complicated printing process, is replaced by new art forms with the change of interior decoration. The Chinese modern art design starts relatively late, so the western modern industrial design products and fashion design conception come into people's life step by step. However, what we should introspect is, when we blindly imitate western modern art design and introduce its design concept, our own national culture is gradually disappeared. The usage of modern art design software and tools indeed widens designers' creative thinking and performance skills, but the form beauty and cultural connotation of national taste can't be replaced by them. Designers must fully grasp historical context and individuality of a nation besides a good artistic accomplishment. Only in this way can they work out excellent works with national characters and times trend.

\section{ARTISTIC CHARACTERISTICS AND AESTHETIC VALUE OF CHINESE FOLK ARTS.}

The Chinese people have created an encyclopedic class culture. The formative arts representing civilian mass culture are called "Chinese folk arts". Comparatively speaking, they differ greatly from those of Professional artists, because they are not used to appreciation, but to meet the need of people's daily life to a large extent, including production and living, life etiquette and related belief and taboo. In many cases, they are 
expressed in very direct ways and means to show the beauty of themselves and beautify goods and surroundings, and they are the ways of laboring people own to voice their pursuit of culture, spirit and ideal life.

Chinese folk arts are rich in types and vary in style. For example, the paper-cut we commonly seen in life, is one of the most popular folk arts, which is widely popularized among people and has a long history. In northern areas of China, people prefer cutting paper into window decoration and putting it on windows, meaning ringing out the Old Year and ringing in the New Year; the famous Chinese New-year wood engraving is a unique and age-old folk art form in China, it mainly popularizes on Spring Festival in rural areas and blesses the New Year. The Chinese New-year wood engraving originates from ancient natural worship and beliefs, and becomes festival customs for people to exorcism and auspice, to beautify life. It is also rich in genres: " Daqing Fengnian Picture" (means celebrating good harvest) shows laboring people ring in Spring Festival and pray a good harvest, its auspicious meaning and prosperous scene add joyful atmosphere to the festival; the Chinese folk shadow play has a strong local characteristic. The folk artisans combine shadow play with puppets and add folk tunes into this art. With the help of light, project screen, stereo and voices of Chinese opera and its various modeling composition, making shadow play the most appealing native art, especially the different genres represented by Shannxi shadow play. In addition, what worth mentioning is the Chinese folk porcelains. Coming from life and rooting in folk, the Chinese folk porcelain is not only aesthetic in art but also practical in life. The Jingde town is called ceramic capital of China, because porcelain productions of this town have plain temperament and artistic appeal that close to nature. Its brief shapes and fluent decoration making it occupy a place in the forest of world art.

We can say that the Chinese folk arts concentrate the balance of Practicability and appreciation of the beauty, and it represents plain aesthetic concept among Chinese folk. The daily used embroidered Chinese-style chest covering wearing close-fittingly is to avoid catching a cold. It is also used as a pledge of promise when a man falls in love with a woman. Some people give it to friends and relatives because the beautiful picture on it can express their wishes. Chinese folk arts are symbolic, their auspicious genres involved always contain auspicious meaning and express by pictures and lines, color and forms. As the representative symbol of laboring people, they fully embody people's great expectations to life. The most distinctive characteristics of Chinese folk arts shapes are expressing meanings by images, composing images with meanings and expressing feelings by objects. To explain briefly, it integrates people's good expectation and kinds of things in life and nature, symbolize auspice and jubilance, meet auspicious fortune. The lotus was used by people to symbol noble moral character. As it was said in Ode to the Lotus Flower, plain and practical, concentrating beauty of kinds of flowers, exactly manifests it lived in silt but not imbrued. As we discussed above, the Chinese New-year wood engraving, one of the genres represented by Kirin brings the child shows auspice and means family prosperity. Therefore, we can find that the essence of Chinese folk arts is that they come from people's daily life, and represent the Chinese primitive culture, they are closely related to people's real life. In terms of shapes, they keep intact freshness and plain without carving or decoration. Their plain contains elaboration and their purity is full of variety. They are typical representatives of Chinese traditional aesthetic conception.

Therefore, we can see that, the Chinese folk arts, as a kind of arts form and arts pattern, by their plentiful spiritual connotation and deep aesthetic meanings, occupy a great place in Chinese traditional cultural arts. As we mentioned above, the paper-cut, the wood engraving and so on, they all reflect people's spiritual appearance, they are filled with people's belief, emotion and entertainment culture. All of these distinctive traditional arts have a far-reaching effect on our modern life undoubtedly.

\section{FUnCTIONS OF CHINESE FOLK ARTS IN MODERN ART DESIGN}

Affected by western art design conception, designers should consider how the Chinese modern art design goes forward. Seeing from its development process, we can find that they are not conflicted with each other. Cultural deposits on Chinese folk arts provide rich things and thoughts for modern art design, so, the designers should take efforts to understand the development process of Chinese folk arts to give more space for modern art design's development.

\section{A. Functions of Chinese Folk Shape Arts in Modern Art Design}

The philosophy basis for Chinese folk shape arts is the value of Yin and Yang. Yin and Yang is usually used to explain whether things face to the sun or not. Simply speaking, Yin refers to things are backward to sun while Yang refers to the opposite direction, which is also used to metaphor cold and warm climate. Just as ancient ideologists analyze things, they conduct analysis from two sides. So Yin and Yang refer to two opposite things in nature world. For Chinese traditional culture, the value of Yin and Yang is applied to both art and folk arts. Such as the structure of the taiji diagram of Yin and Yang, like two fish chasing after each other and merging into a complete graph, we like to call it as the Yin and Yang fish. Careful people can find it through some patterns, symbols and ancient drawings. The most typical thing is character Wan on ancient China's painted pottery with a person's face and fish's lines, so ancient people use it to represent the sun, sunlight and vortex.

For the need of customs and practicability, folk artisans design dynamically in a limited range, they take the best of their imagination and creativity and put their emotion and ideality into works to show people's love to life and expectation to better living conditions. Such as the folk embroidered shoes, designers must arrange design patterns and the auxiliary pattern reasonably in a limited area. The entire design should include the lotus brings children, Harmony lasts for centuries, Gold and jade fill the hall (means abundant wealth) to show the meaning of happiness and peacefulness, highlight the unique adornment of Chinese traditional aesthetic art, so it has a guiding significance for modern art design. In modern interior space design, designers can adopt Chinese folk 
arts to introduce the scenery of nature indoors, integrate modern fashion and the beautiful scenery of nature to reveal people's love and longing for a better life.

\section{B. Functions of Chinese Folk Arts Colors in Modern Art Design}

Color symbol has very important significance in aesthetics of China. Chinese people take the red as a lucky color, and it is mostly used in auspicious occasions. Red paper-cut we mentioned earlier in folk arts is one example. The Chinese people's preference for red also influences modern art design greatly. As we can see in our Olympic Games sports clothes with a red background, which means "with a struggle, take off and victory. Another example is package of moon cake on the Mid-Autumn Festival. It takes the full use of red in the traditional Chinese folk art, the main body colors with red and yellow to resonate with the audience to the hilt and caters to the style of the moon cake package design itself.

Color of Chinese folk arts is reflected by graphic. Folk art color pursues "red and green,, figure a auspice, yellow and pink, exceed altar light", so on the package color of modern nationalized arts, modern commodities can deepen the value of aesthetic with the aid of these traditional colors carrying continuous dynasty change. Such as folk wood engraving, takes "helped shape with color" as the fundament. The dragon and phoenix symbolize Chinese culture. The combination of color and pattern in Chinese folk art makes us feel very kind, so in the modern design art, color can help the traditional symbol to attract audiences, such as in the package of modern wine. Using red and yellow as the main color and matching the traditional folk pictures can foil joyful atmosphere of festival, make people feel better and convey the spiritual needs of audience.

\section{ACKNOWLEDGMENT}

All in all, modern art design absorbs the essence of Chinese folk art is beneficial to aesthetic value of design creation, makes our nationalized modern art design develop more profoundly, and make it more artistic features of the Chinese nation in the world art and design.

\section{REFERENCES}

[1] Wang Shouzhi: A History Of Modern Design, China Youth Publishing Group, Jun, 2007.

[2] Chen Wei: Deconstruction and reconstruction--the traditional Chinese folk arts and contemporary art design. Beauty \& Times. Jul, 2004.

[3] Mao Ping: The influence of Chinese traditional aesthetics to modern design aesthetics. Journal of Changsha Social Work College. Doc. 2006.

[4] Zhang Liansheng: The symbolic significance of Chinese traditional color. Art of Design. Journal of Shandong University of Art \& Design. No.4, 2004. 